\title{
Progressive silicosis in granite workers
}

\author{
W. GRÜNDORFER and A. RABER \\ Silicosis Clinic of the Wiener Gebietskrankenkasse and Department of Occupational Diseases, \\ Allgemeine Unfallversicherungsanstalt, Vienna, Austria
}

\begin{abstract}
Gründorfer, W., and Raber, A. (1970). Brit. J. industr. Med., 27, 110-120. Progressive silicosis in granite workers. The first case of silicosis was discovered in a granite quarry and crushing plant in Lower Austria in 1958 after 30 years of freedom. A routine $x$-ray survey then revealed no further cases but three more cases were discovered in the next two years.

Detailed investigation revealed that these and further cases came from the area where the granite was crushed and loaded. In 10 years 18 cases were found out of a labour force of 170 falling to 120. Average exposure was 15 years and the disease tended to progress. Fifteen of the 18 cases came from the crushing plant where only 20 men were at risk, indicating a very high incidence within 15 years of first exposure.

The risk is attributed to increased size and working capacity of the machines without improved dust suppression. This had led to dust levels over 10 times the accepted maximum in places.

As well as more effective dust suppression, a reduction in staff, the wearing of masks and effective medical supervision of those particularly at risk are recommended.
\end{abstract}

Until 1958 granite work was regarded as a relatively harmless occupation in Austria because of the investigations of Röhrl (1942, 1944). He had found that granite workers in Saxony, Bavaria and Upper Austria had only $0.07 \%$ of severe silicosis in a survey of nearly 4000 workers.

When in 1958 a case of severe silicosis was reported from a granite plant in Lower Austria, this was thought to warrant further investigation.

This case (18, Table 1) was found to have pneumoconiosis type B $\mathrm{n} 2 \mathrm{tb}$. He had worked for less than 14 years at a sizing drum in the crushing plant and also for a short time as a wipper, feeding granite stone into the crusher.

\section{Investigation}

A mass miniature $x$-ray survey was carried out in 1959 but of the 170 workers employed at that time only 125 were $x$-rayed and no cases of silicosis were detected. But within the following two years three more cases of silicosis were reported. One of them had already been diagnosed as silicotuberculosis in
1957 before the interest in this plant was aroused; one had not taken part in the $x$-ray survey and in the third the $x$-ray film was normal in 1959.

The discovery of four cases of silicosis within a short time in a plant where for about 30 years the silicosis risk had been considered minimal, if not negligible, was alarming, especially so since these four men had all worked in the crushing plant where only a small part of the staff is employed. In order to clarify the dust hazards detailed examinations were conducted by the Österreichische Staubbekämpfungsstelle (ÖSBS) in the autumn of 1961. The report by the ÖSBS on dust conditions dated 13 January 1962 reads as follows:

'The plant is engaged in the production of gravel and chippings. The material from the quarries is transported in lorries and dumped on a sloping grate (width $150 \mathrm{~mm}$ ) and comes first to the rough crusher. After the initial screening the material is fed into the various second crushers on conveyor belts. The sifted matter from the sloping grate is immediately washed to clean the dirty soil from it and is thereafter crushed again. The portion containing the smallest stones is further processed into 
chippings and like the other final products is washed again before being stored in the silos. From the silos the material is transported either in freight cars or in lorries.

The output of the plant is exceptionally high. Consequently the machines are of very large dimensions and so is the dust generation. Air samples from the different work rooms and at the machines were taken and the following dust concentrations were found:

At the big crusher, $2100-5000 \mathrm{pp} / \mathrm{cc}$; along the conveyor belt from the big crusher to the uppermost level of the plant, $1550-3500 \mathrm{pp} / \mathrm{cc}$, with an average of $2480 \mathrm{pp} / \mathrm{cc}$; in the room where the motor of the second crushers was located, an average of $4670 \mathrm{pp} / \mathrm{cc}$; in the different workplaces of the second crushing machines, from 3200 to over $10000 \mathrm{pp} / \mathrm{cc}$ - with an average of $7030 \mathrm{pp} / \mathrm{cc}^{1}$

In Austria the maximum allowable concentration in the granite industry is $850 \mathrm{pp} / \mathrm{cc}$ (Drössler, Szongott, Panzer, and Kitzler, 1959). This MAC has been far surpassed. In view of the technological advances made in the production methods there was no need for the staff at that time to perform heavy manual labour any more. The necessary control of the crushing machinery could be performed wearing fine dust respirators.'

Evidently two conclusions had to be drawn from these findings: further mechanization in the production methods must be recommended in order to decrease dust generation in the crusher plant, and the medical control of workers under particularly heavy exposure should be intensified.

Already in 1961, parallel to the dust determiminations in the plant, a second miniature $x$-ray survey was carried out in which two more cases of silicosis were discovered. From then on miniature $x$-ray surveys took place every other year.

In addition, in personal interviews and discussions with the management and representatives of the workers, we tried to find the names of all those who had worked in the dusty places mentioned in the engineering report. If these workers had missed the routine check-up, full-sized radiographs were taken. A few of the exposed persons had left the plant for various reasons. They were traced and examined. Where this was not possible, hospital records, and in one case the death certificate, were checked in order to find any undiscovered silicosis.

The combination of these different methods of investigation proved to be very effective. Within the 10-year follow-up period, the number of cases of granite silicosis from this plant has increased to 18 at the end of 1967.

\section{Description of cases}

Seven of the 18 cases suffered from silicotuberculosis, of whom four have in the meantime died of the

${ }^{1}$ The measurements were performed with a conimeter (Sartorius). The silica content of the granite rock was $67.5 \%$ with $18.0 \%$ free $\mathrm{SiO}_{2}$ (determination by differential thermoanalysis). disease and one from some other cause. The average duration of intensive exposure to granite dust was rather more than 15 years with a minimal exposure of six and a half years. Over one-third of the severe cases of silicosis had been exposed to granite dust for less than 15 years.

A characteristic feature seems to be the comparatively rapid, in some cases even fulminating, progression of silicosis. In 13 of the 18 cases the $x$-ray findings were negative in 1959 . Nine of them were still negative in 1961 and three even in 1965. In four cases no control $x$-ray exists prior to the first diagnosis, and the exact date of onset of the disease is therefore not known.

The result of the analysis of the working history of the persons who had acquired silicosis was very impressive. With the exception of three cases, all of them had worked in these markedly dusty places in the crushing plant: 9 were wippers, feeding broken granite stone into the crushers; 3 worked at the Möll-crusher, 4 at the gyratory crusher and impact breaker and 4 at the sizing drum, also minding the crushing machines. Six men had worked in two of these dusty places and are therefore listed twice. During the last 20 years only five men had worked for a longer period at these places ( 3 as wippers and 2 at the big crusher) without showing any definite signs of silicosis. One of the wippers, born in 1895, could not be traced; in 1954 no silicosis had been present. The two others were $x$-rayed in 1967; one $x$-ray was completely negative, the other showed some interstitial fibrosis(category p1?). One of the two men employed at the big crusher had stopped working there in 1959; his $x$-ray in 1967 showed only minimal interstitial changes. The second man had died of a bronchial carcinoma in 1961 with no silicosis present.

During the last years of this survey a few young men (born in 1932 and 1934) have started working at the big crushers. On miniature $x$-ray screening no pathological lung findings were present. Recently, the work at the crushing plant has been performed mainly by Turkish immigrant workers who, as a rule, do not stay very long at the same working place.

\section{Radiological findings}

In the majority of cases the radiographs have at first a ground glass appearance. A few cases show minimal apical lesions which at first glance suggest a tuberculous process. Within a few years confluent shadows usually develop and a massive fibrosis (13 of the 18 cases, 7 of these complicated by tuberculosis).

Figure $1(\mathrm{a}-\mathrm{c})$ shows the characteristic development from discrete micronodular shadows to massive fibrosis within five years.

Figure $2(\mathrm{a}, \mathrm{b})$ shows the radiograph and tomo- 
TABLE 1

Epidemiological Data of 18 Cases of Granite Silicosis

\begin{tabular}{|c|c|c|c|c|c|c|c|c|c|}
\hline \multirow{2}{*}{ Case } & \multicolumn{2}{|c|}{ Silicosis } & \multirow{2}{*}{$\begin{array}{l}\text { Last } \\
\text { negative } \\
x-\text { ray }\end{array}$} & \multirow{2}{*}{$\begin{array}{c}\text { Rapid } \\
\text { progression }\end{array}$} & \multirow[b]{2}{*}{ Exposure to granite dust } & \multicolumn{2}{|c|}{ Age } & \multirow{2}{*}{$\begin{array}{l}\text { Year } \\
\text { of } \\
\text { death }\end{array}$} & \multirow{2}{*}{$\begin{array}{c}\text { Additional } \\
\text { different } \\
\text { dust } \\
\text { exposure }\end{array}$} \\
\hline & Stage $e^{1}$ & Category $^{2}$ & & & & $\begin{array}{l}\text { diagnosis } \\
\text { of } \\
\text { silicosis }\end{array}$ & $\begin{array}{c}\text { In } \\
1967\end{array}$ & & \\
\hline 1 & I & $\mathrm{m} 2$ & 1961 & & 14 yr crusher-man and wipper & 44 & 47 & & $\begin{array}{l}6 \text { yr brick } \\
\text { works }\end{array}$ \\
\hline $\begin{array}{l}2 \\
3\end{array}$ & $\begin{array}{l}\text { II-III } \\
\text { Si-tb }\end{array}$ & $\begin{array}{l}\text { A m2 } \\
\text { p2 tb }\end{array}$ & $\begin{array}{l}1959 \\
1963\end{array}$ & 1966-II & $\begin{array}{l}20 \text { yr at different places in plant } \\
8 \text { yr loader } \\
2 \frac{1}{2} \text { yr at crusher }\end{array}$ & $\begin{array}{l}70 \\
35\end{array}$ & $\begin{array}{l}71 \\
36\end{array}$ & & 5 yr ceramics \\
\hline 4 & Si-tb & $\mathrm{m} 2 \mathrm{tb}$ & 1961 & 1964-I & 14 yr wipper & 50 & 54 & & - \\
\hline 5 & Si-tb & p3 tb cv & 1961 & 1963-I & $6 \frac{1}{2}$ yr wipper & 58 & & $\begin{array}{c}1967 \\
\text { age } 63^{4}\end{array}$ & 2 yr tunneller \\
\hline $\begin{array}{l}6 \\
7\end{array}$ & $\begin{array}{l}\text { II } \\
\text { II }\end{array}$ & $\begin{array}{l}\text { A n3 } \\
\text { A n3 }\end{array}$ & 1959 & 1961-I & $\begin{array}{l}12 \text { yr wipper } \\
11 \text { yr crusher-man }\end{array}$ & $\begin{array}{l}52^{3} \\
64\end{array}$ & $\begin{array}{l}58 \\
69\end{array}$ & & \\
\hline 8 & Si-tb & $\mathrm{B}(?) \mathrm{n} 3 \mathrm{tb}$ & 1959 & $\begin{array}{l}1962-\mathrm{n} 2 \\
1964-\mathrm{A} \text { n3 }\end{array}$ & 17 yr at 2 nd crushing machines & 54 & & $\begin{array}{l}1967 \\
\text { age } 59\end{array}$ & 一 \\
\hline 9 & I & $\mathrm{m} 2$ & - & & $10 \mathrm{yr}$ at $2 \mathrm{nd}$ crushing machines & 54 & 56 & & $一^{6}$ \\
\hline 10 & $11-111$ & B n3 pl & 一 & & $\begin{array}{l}11 \mathrm{yr} \text { wipper } \\
8 \mathrm{yr} \text { at } 2 \text { nd crushing machines }\end{array}$ & $53^{\circ}$ & 61 & & 一 \\
\hline 11 & I & $\mathrm{m} 2$ & 1965 & & 27 yr wipper and crusher-man & $62^{3}$ & 63 & & $\begin{array}{l}2 \text { yr brown } \\
\text { coal mines }\end{array}$ \\
\hline 12 & Si-tb & B n3 & - & & 28 yr at Möll-crusher & 49 & & $\begin{array}{l}1961 \\
\text { age } 53\end{array}$ & \\
\hline 13 & III & B p3 & 1961 & 1963-I & 27 yr at different work-places & $63^{3}$ & 67 & & $\begin{array}{l}7 \text { yr brown } \\
\text { coal mines }\end{array}$ \\
\hline 14 & II-III & B n 3 & 1959 & 1961-I & 21 yr at Möll-crusher & $49^{3}$ & 55 & & $\begin{array}{l}6 \text { yr different } \\
\text { quarries }\end{array}$ \\
\hline $\begin{array}{l}15 \\
16\end{array}$ & & $\begin{array}{l}\mathrm{n} 2 \\
\mathrm{An} 2 / \mathrm{m} 3\end{array}$ & $\begin{array}{l}1965 \\
1961\end{array}$ & 1964-I & $\begin{array}{l}17 \mathrm{yr} \text { at gyratory crusher } \\
16 \mathrm{yr} \text { at sizing drum }\end{array}$ & $\begin{array}{l}38^{3} \\
44\end{array}$ & $\begin{array}{l}39 \\
47\end{array}$ & & - \\
\hline 17 & Si-tb & A n 3 & 1959 & & 12 yr at Möll-crusher & 56 & & 1964 & \\
\hline 18 & Si-tb & $\begin{array}{l}\mathrm{C}(?) \mathrm{n} 2 \\
\mathrm{tb} \mathrm{cv}\end{array}$ & 一 & & 14 yr at sizing drum & 52 & & $\begin{array}{l}1961 \\
\text { age } 55\end{array}$ & - \\
\hline
\end{tabular}

${ }^{1}$ Old classification.

'ILO classification, Geneva, 1958.

Discovered at miniature $x$-ray screening.

${ }^{4}$ Death not due to silico-tuberculosis.

${ }^{5}$ Last exposure to granite dust in 1945, first diagnosis of silicosis in 1962.

${ }^{6}$ Last exposure to granite dust at age 29, 25 years before first diagnosis of silicosis.

gram of a similar case with an even more rapid development of massive fibrosis within two years.

Figure 3a was originally diagnosed as apical tuberculosis. The case proved to be uncomplicated silicosis with extensive progressive massive fibrosis (Fig. 3b).

A somewhat different type of rapid progression is illustrated by the last case. Figure 4a was taken one year after miniature radiography had been negative and shows diffuse nodular shadows predominantly in the lower lung fields. Four years later (Fig. 4b) there are multiple areas of confluent opacities complicated by tuberculosis with multiple cavitation.

\section{Discussion}

Reviewing the data concerning granite silicosis in different countries, it seems advisable first to compare the results of the classical surveys (up to the early forties) with those of surveys conducted during the last two decades.

The most important of these older surveys were the ones conducted by the U.S. Public Health Service (Hoffman, 1922; Russell, Britten, Thompson, and Bloomfield, 1929; Bloomfield and Dreessen, 1934; Judd, 1939), by Sutherland, Bryson, and Keating (1930) among British granite workers, and the surveys carried out in Germany and Upper Austria by Röhrl in 1942 and 1944. There is a wide gap between the results of the Röhrl survey and those conducted in the United States and in Britain.

The U.S. Public Health Service organized the Vermont survey between 1924 and 1926; it was found that 'practically every pneumatic tool operator could be expected to develop the disease after 15 years of exposure to granite dust'. In 1937 and 
FIG. 1. Case 14. 21 years' exposure at the Möll-crusher, first diagnosed at age 49 (1961).

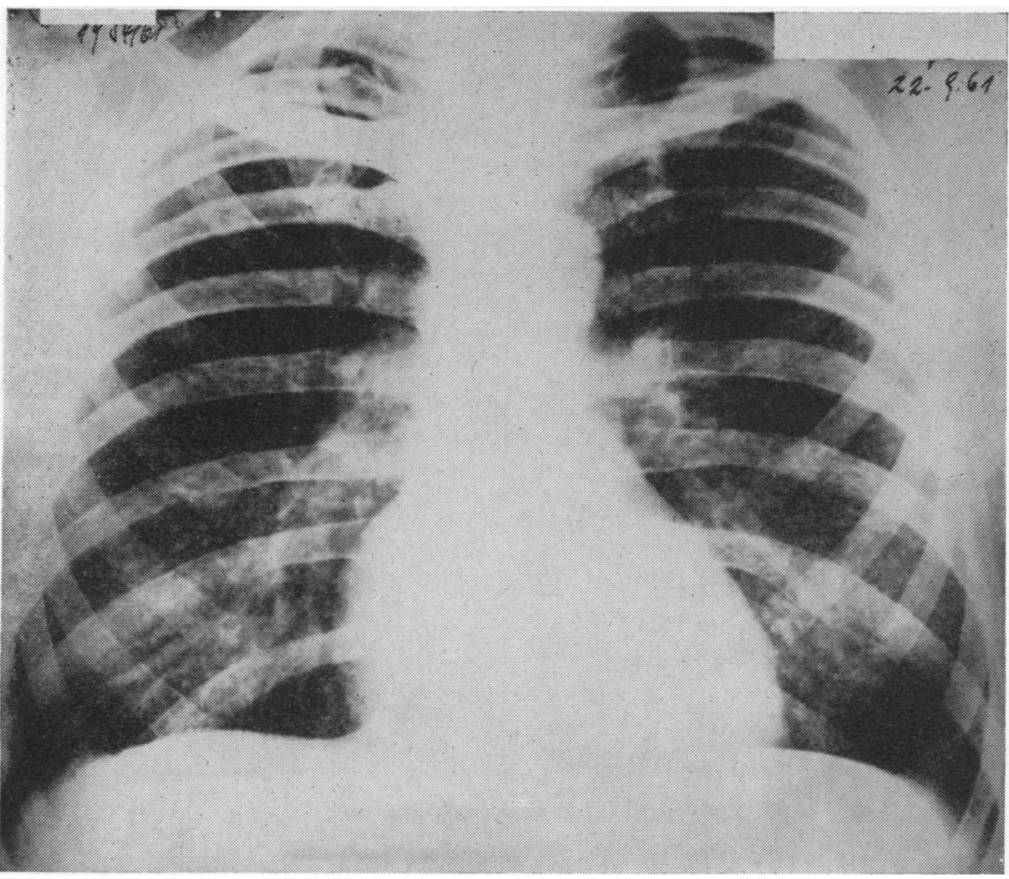

(a) 1961, m2 discrete micronodular shadows.

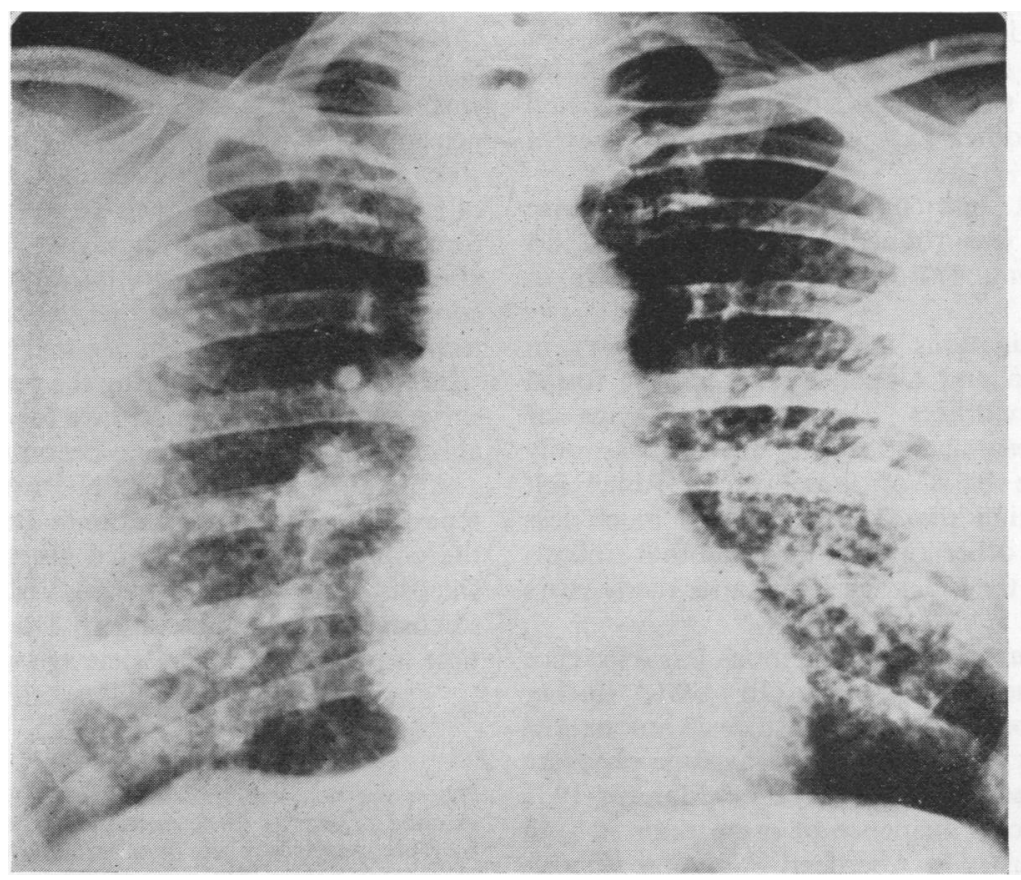

(b) 1965, n3 larger nodular opacities. 


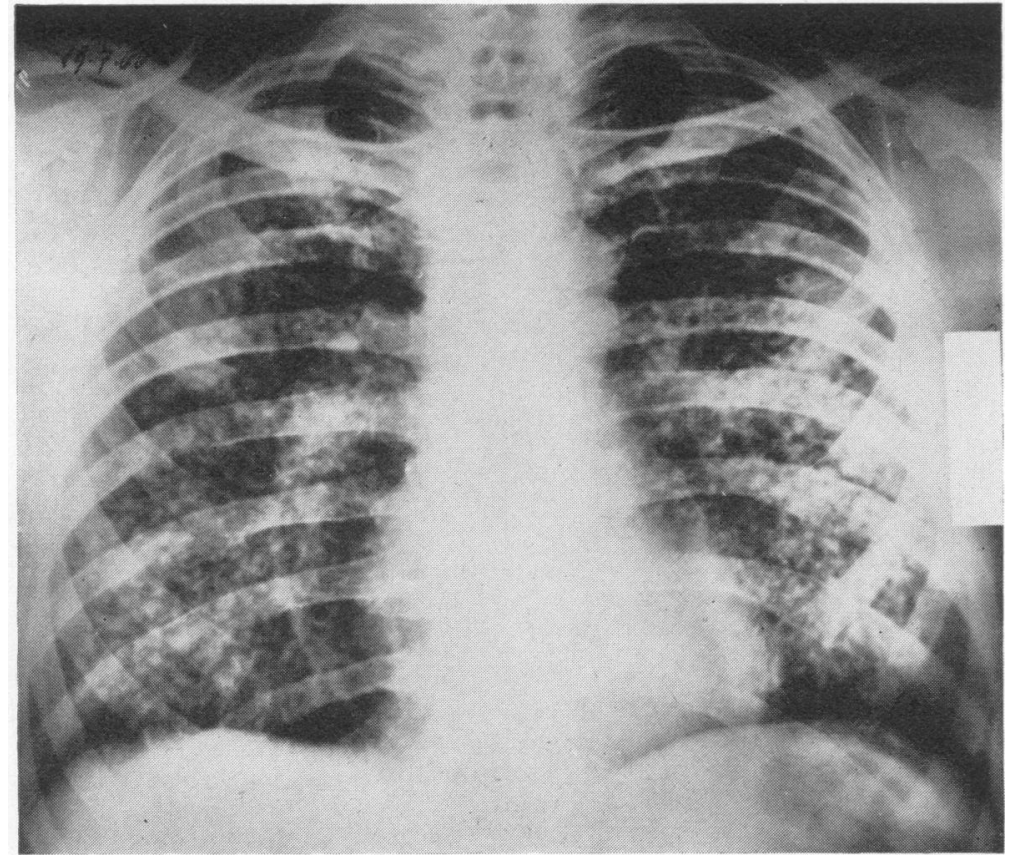

FIG. 1(c) 1966, B n3, PMF and large nodular opacities.

1938 a re-check was performed by the P.H.S. on 116 men, confirming the results of the previous study. It was estimated that at least $26 \%$ of the 2100 workers in the granite sheds in Barre (for methodological reasons the quarries were not included in this study) had simple or complicated silicosis and another $15 \%$ were borderline cases of silicosis.

A somewhat less marked silicosis incidence (around 17\%) was found by Sutherland and his colleagues among 494 British granite workers in 1929.

In his investigations in the granite industry in Saxony, Bavaria and Upper Austria, Röhrl found among 3880 workers a silicosis incidence of $4.6 \%$; the percentage of severe silicosis was only $0.07 \%$. On the basis of these results Röhrl felt justified in stating that granite dust is much less dangerous than other kinds of dust and that silicosis appears only in the older age group after many years of exposure.

The more recent surveys show much less difference in the incidence of silicosis. In 1951, Bucher (Switzerland) found 40 cases of silicosis among 728 granite workers in the Tessin. The average exposure time was between 28 and 37 years. Mair in 1951 reported a silicosis incidence of more than $10 \%$ in the granite industry in Aberdeen. A similar silicosis incidence was found in 1955 by Roche, Minette, and
Baron among French granite workers after between 30 and 40 years' exposure.

Analysing the 1953 statistics of the compensation cases for granite silicosis in Southern Germany, Schneider (1957) found that 330 out of the 7473 workers exposed to granite dust received compensation for silicosis. However, in view of the very strict compensation requirements, the actual number of silicotics was very much greater. Schneider therefore came to the conclusion that 'Röhrl's statement about granite dust being relatively harmless must be considered outdated - particularly where new techniques of production are involved'.

In the last decade - during the period in which this survey was being conducted - a few extensive reports about granite silicosis have been published.

Ahlmark, Bruce, and Nyström (1960, 1965) reported that in Sweden examinations carried out in the granite industry revealed altogether 34 cases of silicosis; out of these four had died by 1965 of either silicosis or silico-tuberculosis. ${ }^{1}$ The average exposure time was 32 years, the average age when the diagnosis

${ }^{1}$ There are no exact statistics about the number of persons exposed to granite dust. According to the statements made by representatives of the Swedish granite industry, there are at present nearly 200 persons working under very dusty conditions during $30-40 \%$ of their working time. 
FIG. 2. Case 13. 27 years' exposure to granite dust at different working places; normal $x$-ray findings in 1961, silicosis (p2) first diagnosed in 1963 at age 63.

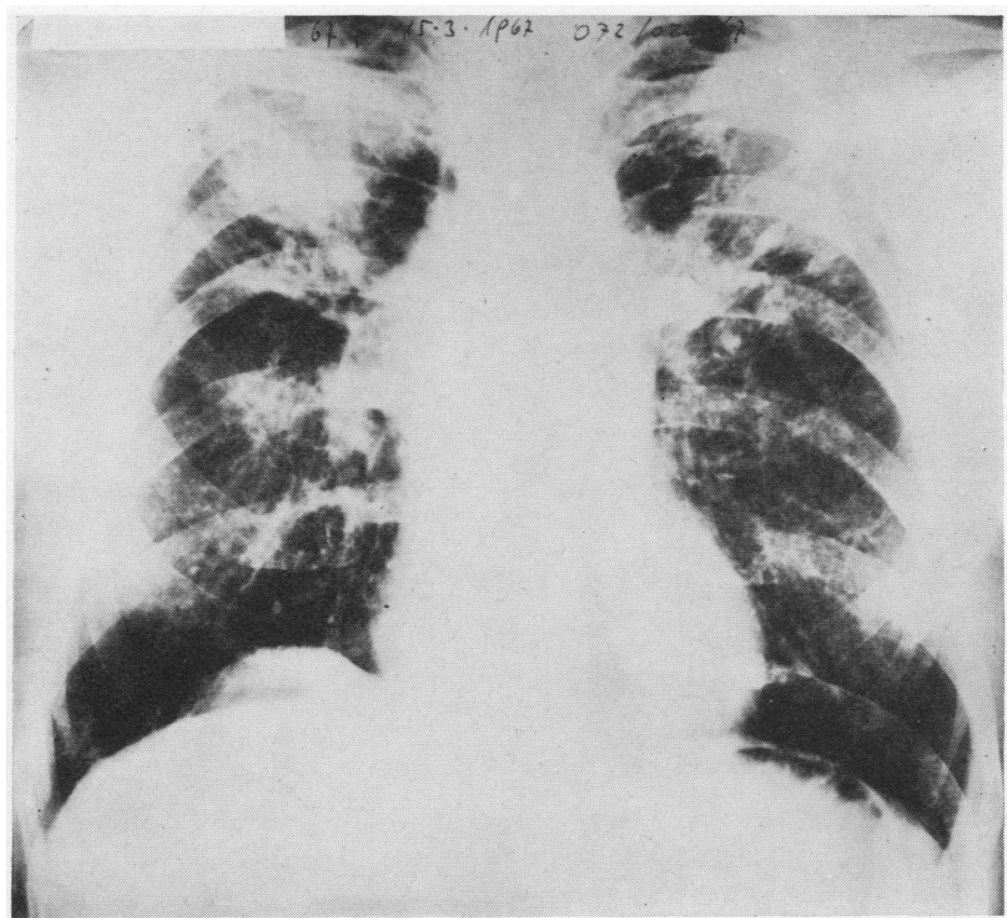

(a) 1967, B p3 em.

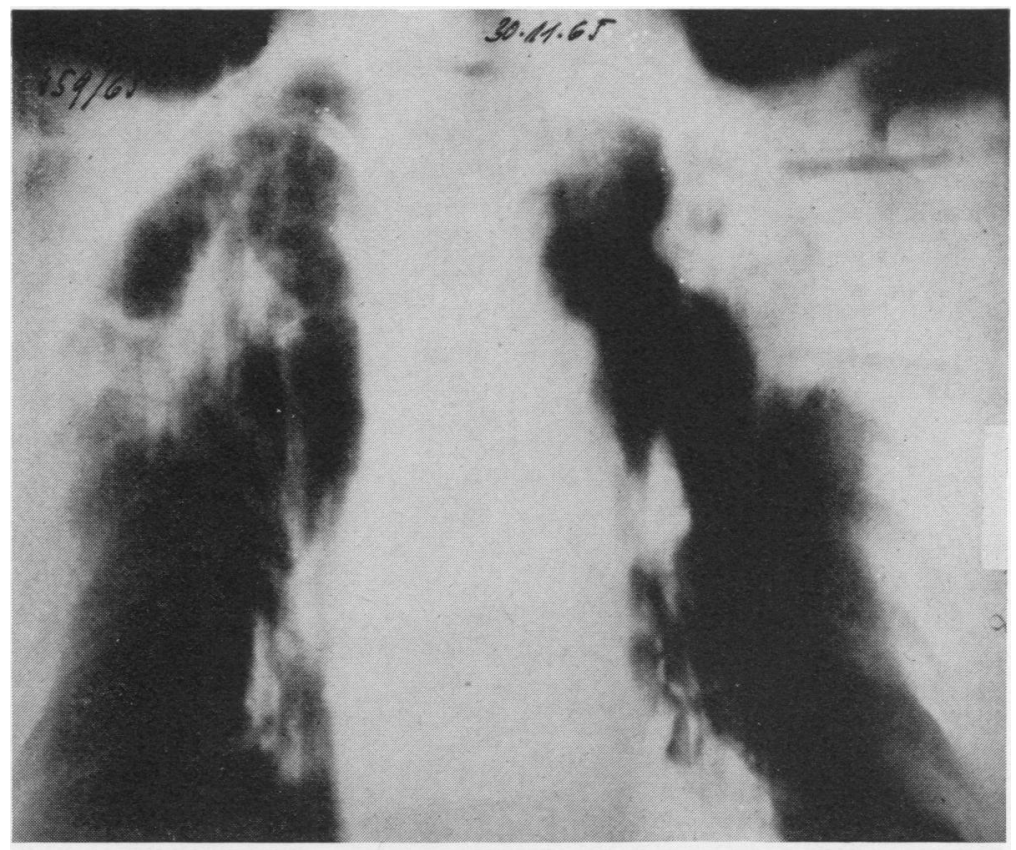

(b) 1965, tomograms of upper lobes (PMF). 
FIG. 3. Case 10. 19 years' exposure - wipper for 11 years and 8 years' work at second crushing machines; first diagnosed at age 53 (1959).

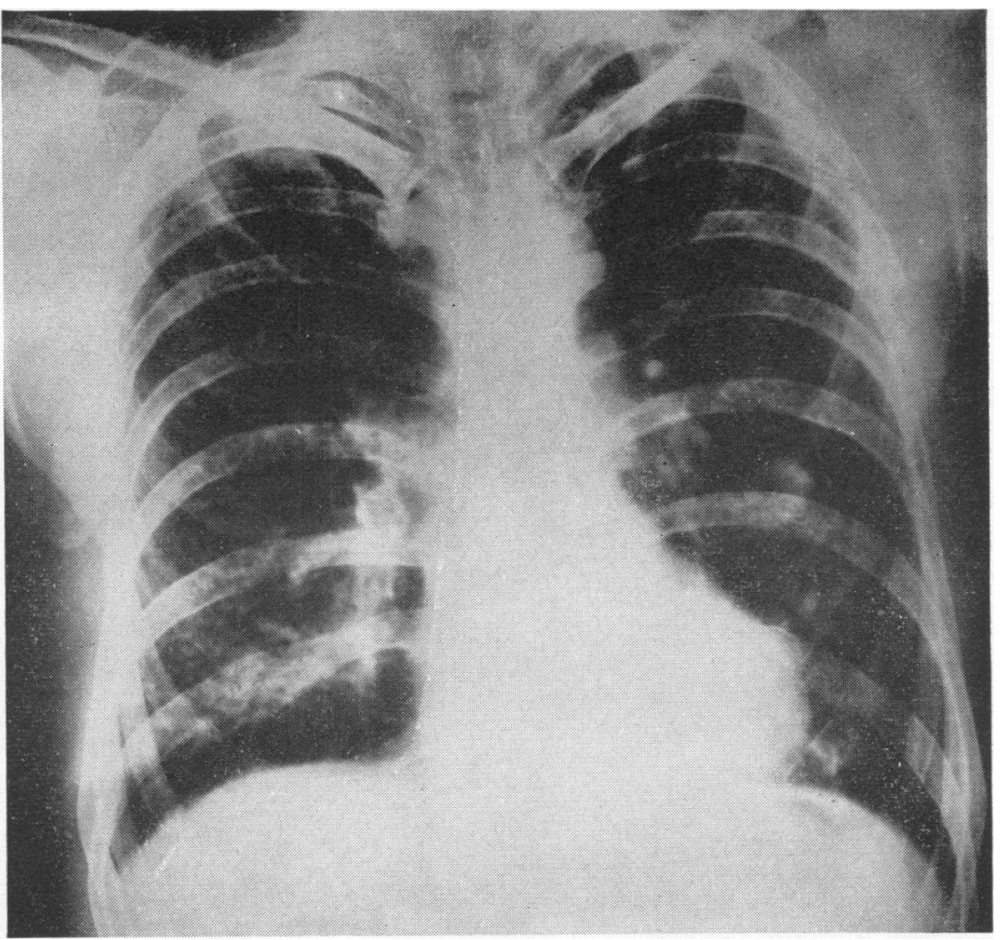

(a) 1960, small opacities below clavicles suggestive of tuberculosis.

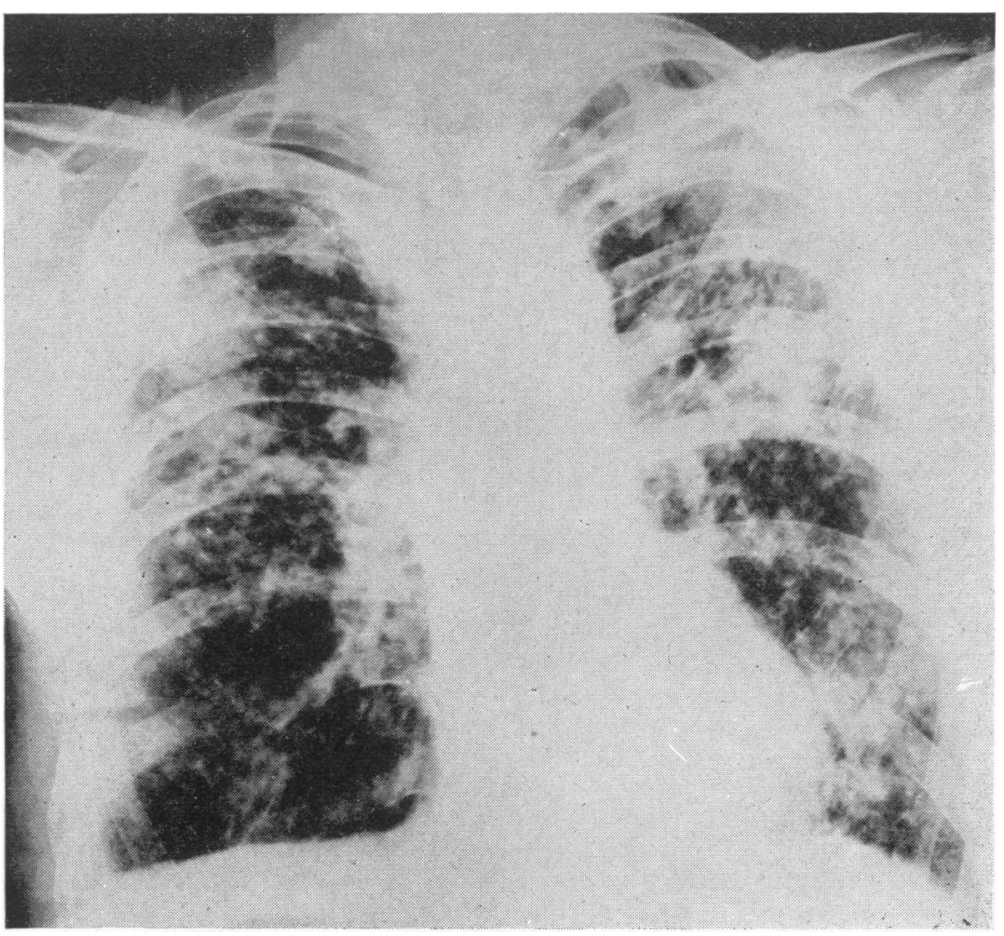

(b) 1966, B n3 (PMF). 
FIG. 4. Case 8. 17 years' exposure at second crushing machines; first diagnosed at age 54 (1962); died at age 59.

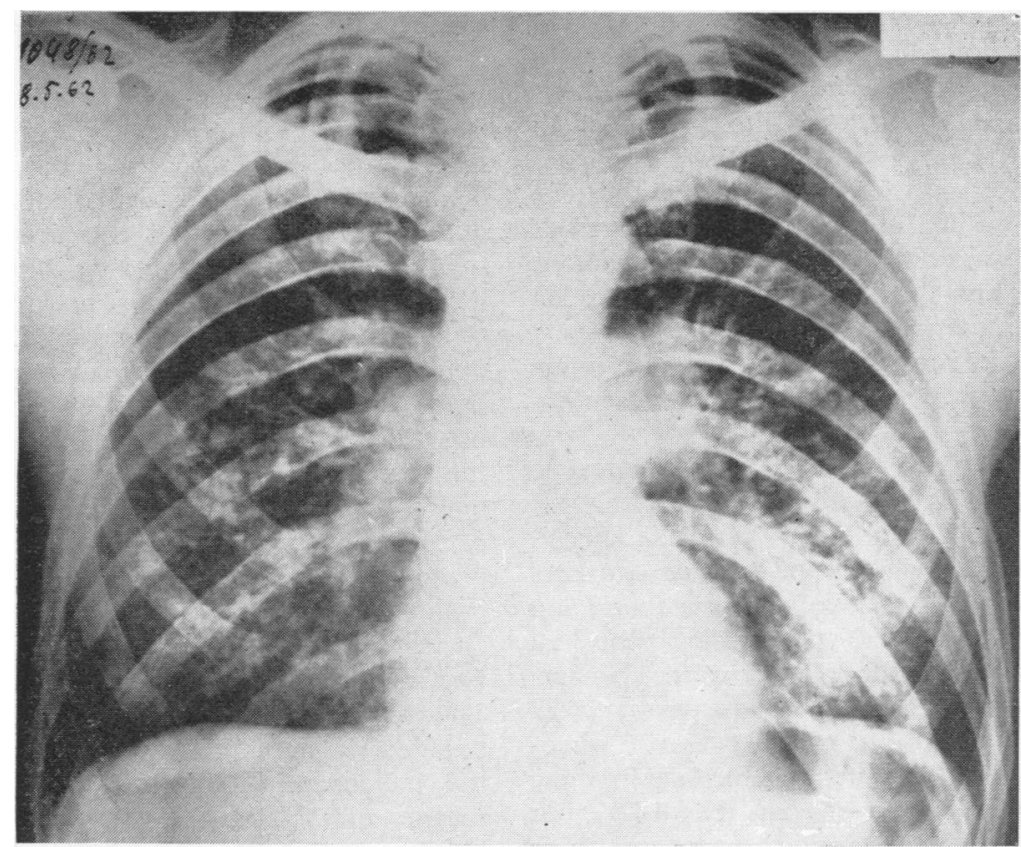

(a) $1962, \mathrm{n} 3$.

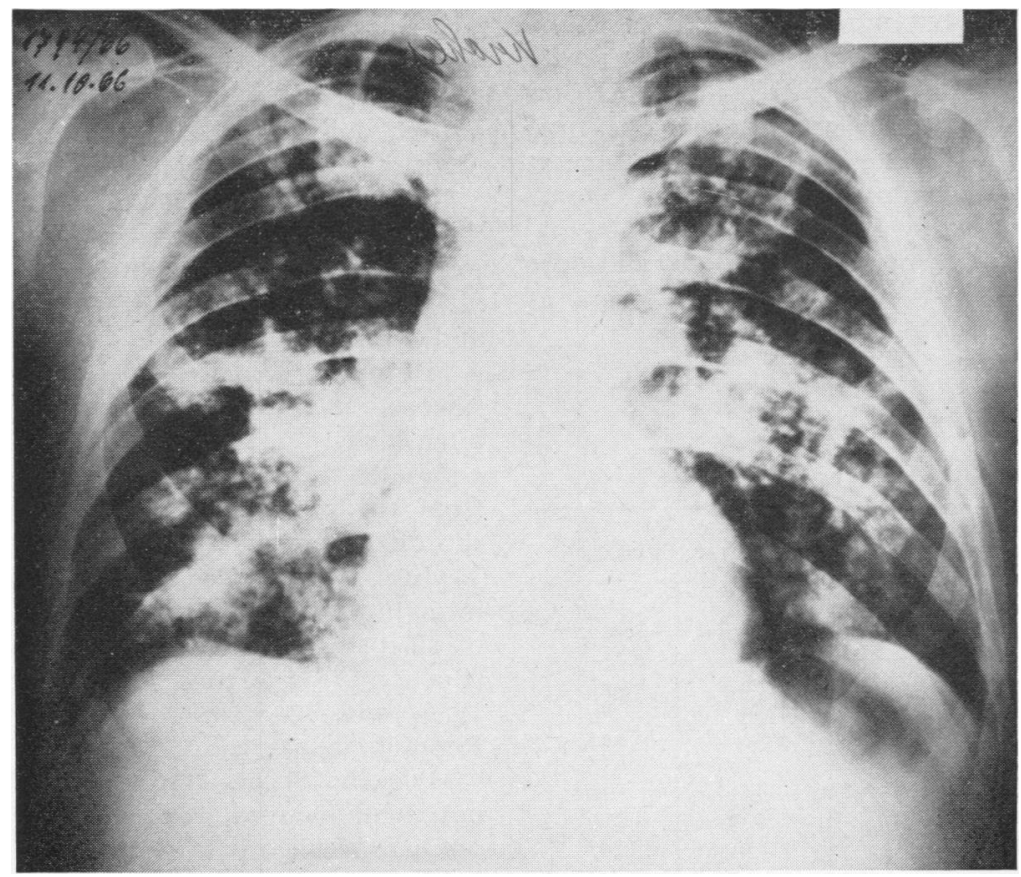

(b) 1966, B n3 tb multiple areas of confluent opacities (PMF). 
was first made was 55 years. The silicosis showed a 'pronounced tendency to progression'.

Hale and Sheers (1963) reported a 10-year followup of granite workers in the West of England. In 1951, 210 granite masons (84\% of the total group) were examined and 37 cases of silicosis found, an incidence of $17.6 \%$. In 1961,132 of these masons ( $94 \%$ of the total group) were re-examined and nine additional cases of silicosis discovered. 'The exposure in the 1961 cases was comparable with that of similar cases in 1951. Thus the risk has not been much reduced over this period.' Twenty-eight of the 37 cases of silicosis diagnosed in 1951 were still living ( 2 had died of this disease) and 13 showed radiological progression.

In his survey of silicosis in the German Democratic Republic, Sepke (1965) reported the findings in granite plants located mainly in the Niederlausitz. Three thousand and eighty-nine granite workers were examined and 79 cases of silicosis found, an incidence of $2.6 \%$. Nearly 20 years earlier Röhrl had found in the same granite plants in the Niederlausitz (Saxony) 106 cases of silicosis among 2227 granite workers, not counting the cases of silicotuberculosis which Röhrl did not include in these statistics. The silicosis incidence was then $4.7 \%$; but besides the 79 cases who were still at dusty work there were silicotics who had left this industry. Sixty-two percent of these 161 men were retired and the remaining $38 \%$ were now working at places without silicosis hazards. If the 161 cases of silicosis already known from previous examinations are added to the 79 men still employed in the granite industry, the final result about trebles the silicosis incidence and almost reaches the $10 \%$ level. The exposure time ranges from 27 to 34 years and the average age at the time of the first diagnosis of silicosis was 55 to 61 years.

There has been a remarkable shift to the more severe forms of silicosis within the last 20 years, as shown in Table 2.

TABLE 2

Granite Silicosis in the Niederlausitz

\begin{tabular}{|c|c|c|c|}
\hline \multirow{2}{*}{ Category } & \multirow{2}{*}{$\begin{array}{c}\text { (Röhrl, } \\
\text { 1942, 1944) } \\
\text { Still } \\
\text { employed }\end{array}$} & \multicolumn{2}{|c|}{ (Sepke, 1965) } \\
\hline & & $\begin{array}{c}\text { Still } \\
\text { employed }\end{array}$ & $\begin{array}{c}\text { Left } \\
\text { industry }\end{array}$ \\
\hline $\begin{array}{c}\text { 0-I } \\
\text { I } \\
\text { I-II } \\
\text { II } \\
\text { II-III } \\
\text { III } \\
\text { Silico tuberculosis }\end{array}$ & $\begin{array}{r}78 \\
18 \\
8 \\
1 \\
1 \\
0 \\
\text { nk }\end{array}$ & $\begin{array}{r}\text { nk } \\
34 \\
6 \\
7 \\
15 \\
11 \\
6\end{array}$ & $\begin{array}{l}\text { nk } \\
49 \\
15 \\
15 \\
10 \\
29 \\
43\end{array}$ \\
\hline
\end{tabular}

$\mathrm{nk}=$ not known.
In our survey the incidence lies also within the $10 \%$ range. The percentage of the severe forms of silicosis (14 out of 18) even surpasses the figures reported by Sepke, provided conclusions from such small numbers as ours are permitted.

The three areas thoroughly investigated earlier by Röhrl, the surveys carried out in Bavaria by Schneider, in Saxony by Sepke and our recent results obtained in an Austrian granite plant have shown that the conclusions of Röhrl about the relative harmlessness of granite dust are no longer valid. On this point, therefore, no serious differences of opinion exist at this time; however, a useful comparison of the actual hazard due to granite dust between the different countries is problematical on the basis of the data available. For example, the figures on incidence, to take one of the many parameters, have been obtained by different methods of epidemiological research, rendering a statistical evaluation questionable.

\section{The special hazard in gravel production}

The overall silicosis statistics in our survey are liable to give a wrong impression. They are the sum total of the incidence at specific working places, which reaches almost the $100 \%$ limit, and the very low incidence at the great majority of working places where the silicosis risk is indeed fairly small.

Fifteen of the 20 men who had worked in the crushing plant for a longer period of time suffered from silicosis. This exceptionally high silicosis incidence at certain places of work raised the question whether this was due to particular local conditions of operation or whether it is characteristic of this particular type of production throughout the granite industry.

In the literature we found only a few references to this problem. To our knowledge, Schneider (1957) was the first to draw attention to the special hazards involved in the mechanized production of gravel and chippings. As early as 1957 he stated that 'there is in future a danger of a considerable incidence of silicosis if gravel production from granite is intensified'.

Besides the high incidence of silicosis, the cases from the crushing plant presented a remarkably short exposure time.

Most of the surveys report a surprisingly similar mean time of exposure required for the establishment of silicosis. It was 28 to 37 years in Switzerland (Bucher, 1951), 30 to 40 years in France (Roche et al., 1955) and 32 years in the German Democratic Republic (Sepke, 1965).

Hale and Sheers (1963) in the British survey do not mention a mean exposure time but there was not one case of silicosis with less than 15 years' exposure.

In contrast to these figures the mean exposure time in the plant investigated by us was about 15 
years with a minimum of $6 \frac{1}{2}$ years; over one-third of the severe cases of silicosis had been exposed to granite dust for less than 15 years. It is of interest that Ahlman ${ }^{1}$ found in Finland a mean exposure time of $22 \frac{1}{2}$ years in his 126 cases of silicosis; but the six cases who had acquired the silicosis working at crushing plants (having therefore performed a similar type of work to our silicosis cases) were exposed for a much shorter period (between 7 and 18 years).

Of course, the difference in the conditions under which granite crushing is carried out is important. In Finland the crushing plants are operated continuously, whereas in Sweden the main reason for the comparatively low incidence seems to be the fact 'that in many places stone crushing is done only for short periods each year and by casual labour. Consequently, the total exposure to dust in the individual case is generally insufficient to cause silicosis' (Ahlmark et al., 1960).

Conditions in England are similar. Hale and Sheers (1963) write: 'In some of the larger yards there is a building which houses the crusher . . . which produces ballast, chips, gravel etc. as a byproduct from the waste granite ... the workers with the crushers are unskilled and tend to move from job to job, within or out of the industry.'

Thus the principal difference is to be found in the fact that in one case we are dealing with the byproduct from the waste of the working of granite and in the other with the principal product turned out by a stable group of workers who therefore are continuously exposed to dust.

In addition, the rapid increase in the demand for crushed granite as road building material and for spreading loosely on the surface, especially for mountain roads in winter, has in some countries led to an expansion in the industry and to the introduction of bigger machines. This has raised the dust levels far above the safety limits.

\section{Problems of dust control}

Drinker and Hatch (1954) demonstrated the obstacles to effective dust control. Among other things they stated: 'We have seen many plants, both old and new, in which attempts to achieve good dust control have not given adequate results . . . Crusher houses are a good example - they may handle anything from 100 to 10000 tons of rock a day and be operated by a few full-time men. . . . If dustiness is to be kept constantly below the 10-million particles per cubic foot level the cost of dust control can become excessive. It is better in such a case to install control at the 50 to 100 million ppcf level and

\footnotetext{
'The report of Ahlman on 'Silicosis in Finland' appeared at the beginning of 1968 after our investigations had been completed.
}

require the intermittent use of good respirators.'

The conclusions of the engineering report on dust conditions in the crushing plant in Lower Austria in 1962 are almost identical with the above cited statement. In certain places the MAC values are exceeded up to 10 times.

A few of the exceedingly dusty procedures were discontinued because of further mechanization; in other cases the dustiness was diminished through preventive engineering measures. However, since the report states that 'the necessary control of the crushing machinery can be performed wearing fine dust respirators' the main emphasis still lies with the individual dust prophylaxis of the persons exposed. Interviews and discussions with the men still working at the places in question or after retirement produced the almost unanimous answer: the men did not wear these respirators except for very short periods. They all declared that, especially for older people, the continuous use of these respirators decreased working capacity to such an extent that it considerably affected their pay.

The need for intensive medical control

Even if it were possible in future to keep dust generation to a bearable level, we have to expect a considerable increase in the number of new cases of silicosis for some time. Routine $x$-ray screening is probably insufficient to discover them even if these examinations are carried out at yearly intervals. Routine $x$-rays never reach $100 \%$ of the workers endangered by dust because of absences due to holidays, sickness, etc. In the granite plant covered by this report they never reached more than twothirds of the staff, even though $x$-ray examinations for dust-exposed persons are mandatory in Austria. Since only a small section of the staff, sometimes only single individuals, are engaged in stone crushing in the smaller plants, it may happen that those most endangered by the dust do not undergo $x$-ray control for a considerable period of time. (Only six of our eighteen cases of silicosis were found by $x$-ray screening.)

Based on the experience of an intensive check-up, as reported above, we tried to have the following measures implemented in Austria:

1. Full-sized $x$-ray films should be made of all employees working in crushing plants or at a crushing machine who have missed the routine examination. (This raises certain difficulties because most granite plants are located away from urban facilities or hospitals where these examinations can be carried out.)

2. Every effort should be made to check regularly those persons who had worked at such dusty places for a longer period and who had left the granite industry before pulmonary $x$-ray changes were either present or discovered. 


\section{References}

Ahlman, K. (1968). Silicosis in Finland. Work-Environment-Health, 4, Suppl. 1.

Ahlmark, A., Bruce, T., and Nyström, A. (1960). Silicosis and Other Pneumoconioses in Sweden. Scandinavian University Books, Stockholm.

- $\longrightarrow$, and - (1965). Silicosis from quarrying and working of granite. Brit. J. industr. Med., 22, 285-290.

Bloomfield, J. J., and Dreessen, W. C. (1934). Silicosis among granite quarriers. Publ. Hlth Rep. (Wash.), 49, 679-684.

Bucher, J. (1951). Die Silikose der Granitsteinhauer im Tessin. Unfallmed. Berufskr, 44, 225-234, 300-311.

Drinker, P., and Hatch, T. (1954). Industrial Dust, 2nd ed. McGrawHill, New York.

Drössler, H., Szongott, M., Panzer, E., and Kitzler, W. (1959). Uber die Ermittlung der "kritischen Staubdichte" in Osterreich. Staub, 19, 288-290.

Hale, L. W., and Sheers, G. (1963). Silicosis in West Country granite workers. Brit. J. industr. Med., 20, 218-225.

Hoffman, F. L. (1922). The Problem of Dust Phthisis in the Granitestone Industry. Bull. U.S. Bureau of Labor Statistics, No. 293, Washington.
Judd, L. E. (1939). Clinical picture and $X$-ray findings of granite shed workers in Vermont. In Fourth Saranac Lab. Symp. on Silicosis. pp. 207-216.

Mair, A. (1951). A survey of the granite industry in Aberdeen with reference to silicosis. Edinb. med. J., N.S. 58, 457-480.

Roche, L., Minette, A., and Baron, J. (1955). Trauvaux récents sur la silicose pulmonaire. Arch. Mal. prof., 16, 348-362.

Röhrl, W. (1942). Bericht über eine Reihenuntersuchung von Granitarbeitern. Staub, Heft 18, pp. 513-519.

_ (1944). Zweiter Bericht über Reihenuntersuchungen von Granitarbeitern. Staub, Heft 21, pp. 152-156.

(1947). Die Granitsilikose. Arbeitsmedizin, Heft 23. Barth, Leipzig.

, Britten, R. H., Thompson, L. R., and Bloomfield, J. J. (1929). The Health of Workers in Dusty Trades II. Exposure to Siliceous Dust (Granite Industry). Publ. Hlth Bull. (Wash.), No. 187.

Schneider, H. (1957). Die Silikosegefährdung in der bayrischen Granitindustrie. Staub, Heft 50, pp. 450-456.

Sepke, G. (1965). Die Steinbruchsilikosen und ihre Bekämpfung. Fischer, Jena.

Sutherland, C. L., Bryson, S., and Keating, N. (1930). Report on the Occurrence of Silicosis amongst Granite Workers. H.M.S.O., London.

Received for publication June 5, 1969. 